\title{
On the accuracy of arrival azimuth determination of sprite-associated lightning flashes by Earth-ionosphere cavity resonances
}

\author{
Martin Füllekrug and Steven C. Reising \\ STAR Laboratory, Stanford University, California
}

Walter A. Lyons

ASTeR Inc., Ft. Collins, Colorado

\begin{abstract}
Horizontal magnetic field variations in the frequency range of the Earth-ionosphere cavity resonances are observed at Silberborn, Germany, simultaneous with 19 sprite-associated lightning flashes in the midwestern United States, on July 15, 1995. The measured horizontal magnetic intensities are linearly related to the horizontal magnetic intensities of slow tails of radio atmospherics which were simultaneously recorded at Palmer Station, Antarctica. Enhancement of the Earth-ionosphere cavity resonances is vcrificd by spectral analysis, and the measured arrival azimuths are in agreement with the expected orientation of the Poynting vector along the great-circle path. The estimated accuracy of the arrival azimuth determination is on the order of $\pm 5^{\circ}$.
\end{abstract}

\section{Introduction}

Transient optical emissions in the mesosphere, denoted sprites, have been observed in a series of campaigns in the United States since the summer of 1993 [Sentman and Wescott, 1993; Lyons, 1994; Winckler, 1995]. The occurrence of sprites is accompanied by strong positive cloud-to-ground lightning discharges within a time interval of $\pm 70 \mathrm{~ms}$ [Reising et al., 1996], while triangulated sprite locations appear laterally within thunderstorm areas where the ratio of positive to negative cloud-to-ground lightning is higher than usual [Sentman et al., 1995; Lyons, 1996]. These lightning flashes produce electromagnetic pulses which contain considerable energy in the frequency range of the Earthionosphere cavity resonances $(6-60 \mathrm{~Hz})$ [Boccippio et al., 1995]. Arrival azimuth determination of transient excitations of the Earth-ionosphere cavity resonances has been used for locating lightning discharges from single station measurements [Jones and Kcmp, 1970; Kemp, 1971]. This contribution validates arrival azimuth determination using Earth-ionosphere cavity resonances through an experimental estimation of the accuracy, taking advantage of precise times and locations of sprite-associated lightning flashes provided by the National Lightning Detection Network (NLDN).

Low light level TV (LLTV) camera observations by ASTeR, Inc., recorded sprite events above a mesoscale

Copyright 1996 by the American Geophysical Union.

Paper number 96GL03538.

0094-8534/96/96GL-03538\$05.00 convective system in the midwestern United States on July 15, 1995. Nineteen events were available at the time of analysis and are investigated in this paper. The NLDN identified the times and locations of the spriteassociated lightning flashes (Table 1, columns 2-4) with a precision of $\pm 1 \mathrm{~ms}$ and $\pm 1 \mathrm{~km}$ respectively. When the NLDN did not report a flash, no entry is given in the NLDN columns, and timing is provided by radioatmospheric observations at Palmer Station, Antarctica $\left(64.8^{\circ} \mathrm{S}, 64.0^{\circ} \mathrm{W}\right)$, after correction for propagation delay [Reising et al., 1996]. LLTV observations reported 'elves' [Fukunishi et al., 1996] instead of sprites for events No. 7 and 8 in Table 1.

The Institut für Geophysik Göttingen performs continuous measurements of the horizontal magnetic field components from 0.1 to $20 \mathrm{~Hz}$ with a sampling rate of $100 \mathrm{~Hz}$ at Silberborn $\left(51.8^{\circ} \mathrm{N}, 9.5^{\circ} \mathrm{E}\right)$ [Füllekrug, 1995]. The instrument location at an angular great-circle distancc of $\sim 71.5^{\circ}$ from the sprite-producing thunderstorm is well suited for detection of the Earth-ionosphere cavity resonances, which exhibit an amplitude maximum at $90^{\circ}$ from the source. The polarity of the induction coils is set to be positive in the magnetic north $\left(B_{x}\right)$ and east $\left(B_{y}\right)$ directions, according to magnetotelluric conventions. Timing is taken from the German time standard DCF77 in the low frequency range (77.5 $\mathrm{kHz}$ ) and is precise to $<1 \mathrm{~ms}$. Broadband ELF/VLF measurements $(\sim 300 \mathrm{~Hz}$ to $20 \mathrm{kHz})$ at Palmer Station, Antarctica, simultaneously observed the radio atmospheric waveforms [Reising et al., 1996]. The time series were low-pass filtered with a cutoff frequency of 1 $\mathrm{kHz}$ for further analysis, and the resulting waveform has a signal-to-noise ratio of $>15 \mathrm{~dB}$. The remaining slow tail is the ELF portion of a radio atmospheric, which is localized in time to $<10 \mathrm{~ms}$.

\section{Excitation of the Earth-ionosphere cavity resonances}

Horizontal magnetic field variations at Silberborn show discrete events superimposed upon a weak natural noise background. As an example of the observed waveforms, the $B_{x}$ and $B_{y}$ components of event No. 5 are displayed in Figure 1. Both components exhibit an onset at 0.00 seconds, the time of the sprite occurrence, and oscillate at $8 \mathrm{~Hz}$, hence denoted a quiet burst. Their phase is constant over several cycles, and defines the orientation of the wavefront. The mean decay time of the 
Table 1. Occurrences of sprite-associated lightning flashes in the midwestern United States on July 15, 1995 (columns 2-4) and the NLDN-measured peak current (column 5 ) in kA. Horizontal magnetic intensities $B_{h}$ in pT from ELF slow tails in Antarctica (column 6) and from the Earth-ionosphere cavity resonances (EICR) in Germany (column 7), which are divided into two groups of high, labeled 'o', and low, labeled ' $x$ ', intensity events (column 8). Spectral estimates for the first $\left(f_{8}\right)$ and second $\left(f_{14}\right)$ Earth-ionosphere cavity resonances are given in column 9 and 10 respectively in $\mathrm{pT} / \operatorname{Sqrt}(\mathrm{IIz})$.

\begin{tabular}{|c|c|c|c|c|c|c|c|c|c|}
\hline \multirow[b]{2}{*}{ No. } & \multirow[b]{2}{*}{ time (UT) } & \multicolumn{3}{|c|}{ NLDN } & \multirow{2}{*}{$\begin{array}{c}\mathrm{ELF} \\
B_{h}\end{array}$} & \multicolumn{4}{|c|}{ EICR } \\
\hline & & Lat. & Long. & $I_{\text {peak }}$ & & $B_{h}$ & group & $B_{h}\left(f_{8}\right)$ & $B_{h}\left(f_{14}\right)$ \\
\hline 1 & $05: 48: 41.270$ & 40.89 & -101.41 & 45.8 & 3.2 & 3.8 & $x$ & 0.8 & 2.3 \\
\hline 2 & $05: 57: 00.635$ & 40.91 & -101.47 & 79.3 & 10.6 & 10.2 & o & 6.0 & 4.6 \\
\hline 3 & $06: 00: 26.381$ & 41.02 & -101.14 & 82.2 & 5.9 & 7.5 & o & 10.9 & 5.3 \\
\hline 4 & $06: 04: 01.526$ & 40.53 & -101.51 & 103.3 & 25.2 & 17.6 & o & 10.7 & 4.4 \\
\hline 5 & $06: 10: 22.387$ & 11.02 & -101.10 & 162.5 & 21.5 & 8.9 & o & 7.5 & 2.7 \\
\hline 6 & $06: 18: 57.417$ & 40.99 & -101.03 & 45.3 & 3.6 & 8.0 & o & 6.0 & 4.2 \\
\hline 7 & $06: 22: 02.658$ & - & - & - & 6.5 & 3.9 & $x$ & 2.8 & 2.1 \\
\hline 8 & $06: 34: 46.359$ & 42.80 & -98.51 & 162.6 & 14.8 & 6.9 & o & 3.4 & 3.2 \\
\hline 9 & $06: 46: 52.671$ & 41.31 & -101.08 & 45.0 & 3.1 & 3.4 & $x$ & 0.9 & 2.1 \\
\hline 10 & $06: 48: 49.827$ & - & - & - & 1.1 & 2.1 & $x$ & 0.7 & 1.2 \\
\hline 11 & $06: 58: 07.936$ & 42.17 & -100.29 & 22.0 & 2.4 & 4.0 & $x$ & 1.6 & 0.8 \\
\hline 12 & $07: 01: 47.053$ & 41.39 & -101.25 & 26.1 & 1.7 & 3.1 & $x$ & 1.4 & 1.8 \\
\hline 13 & 07:04:19.707 & 42.25 & -100.24 & 49.2 & 6.5 & 6.3 & o & 2.9 & 1.8 \\
\hline 14 & $07: 06: 30.261$ & 41.75 & -100.70 & 33.2 & 2.5 & 4.9 & $x$ & 2.5 & 1.9 \\
\hline 15 & $07: 07: 26.607$ & 42.15 & -100.25 & 35.0 & 4.5 & 6.7 & o & 3.5 & 2.0 \\
\hline 16 & $07: 08: 30.114$ & 42.00 & -100.83 & 66.2 & 7.7 & 9.2 & o & 1.8 & 2.3 \\
\hline 17 & $07: 09: 52.211$ & - & - & - & 2.7 & 2.3 & $x$ & 2.2 & 1.6 \\
\hline 18 & $07: 11: 18.500$ & 11.50 & -101.18 & 28.0 & 5.4 & 5.4 & $x$ & 3.3 & 1.8 \\
\hline 19 & $07: 12: 49.430$ & 42.24 & -100.16 & 36.3 & 3.3 & 3.1 & $x$ & 1.6 & 1.4 \\
\hline
\end{tabular}

discrete events is on the order of 0.50 seconds. A useful measure of the received energy is the 0.25 -second mean of the horizontal magnetic intensity

$$
B_{h}=<\sqrt{B_{x}^{2}(t)+B_{y}^{2}(t)}>
$$

(Table 1, column 7) beginning at the time of the spriteassociated lightning flashes. The horizontal magnetic intensities are related to the NLDN peak currents (Table 1 , column 5 ), measured $<400 \mathrm{~km}$ from the sprite-

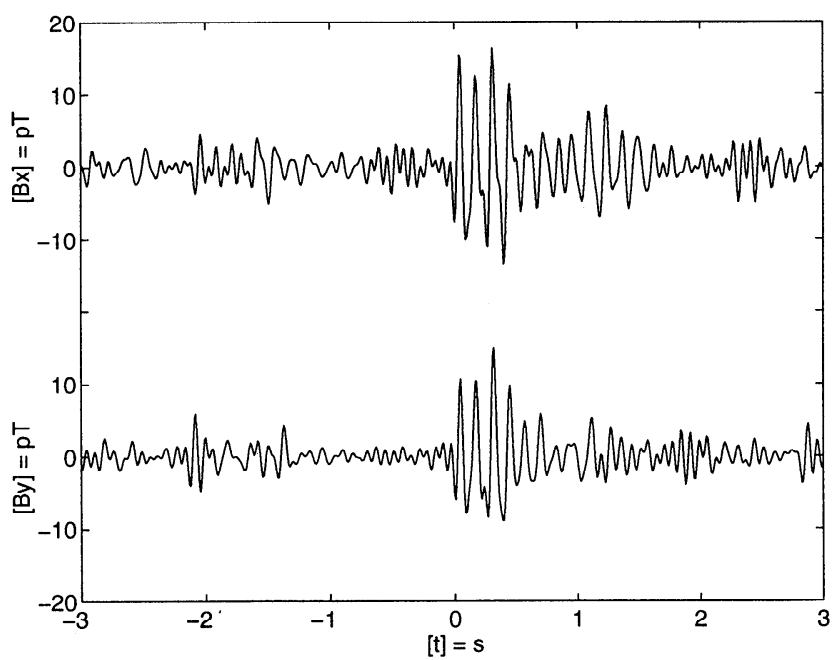

Figure 1. Time series of the magnetic north $\left(B_{x}\right)$ and east $\left(B_{y}\right)$ components at Silberborn around sprite event No. 5 at 0.00 seconds. associated lightning flashes, with a correlation coefficient of 0.52 . The slow-tail energy is quantified by the 10-ms mean of the horizontal magnetic intensity $B_{h}$ ('Table 1, column 6). The horizontal magnetic intensities of the Earth-ionosphere cavity resonances and of the slow tails exhibit similar magnitudes and are linearly related with a correlation coefficient of 0.82 (see Figure 2). The Earth-ionosphere cavity resonances are more or less hidden in ongoing atmospheric and mag-

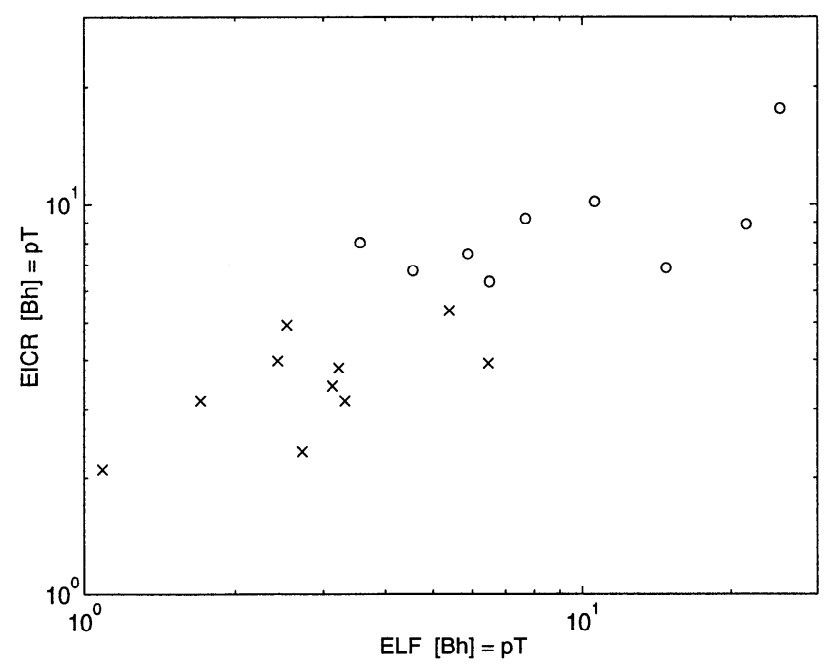

Figure 2. Mean horizontal magnetic intensities $B_{h}$ of the Earth-ionosphere cavity resonances (EICR) (high intensity events are labeled 'o' and low intensity events are labeled ' $X$ ') at Silberborn, Germany, and ELF slow tails at Palmer Station, Antarctica. 
netospheric noise. The natural noise background at Silberborn is on the order of $B_{h} \approx 2 \mathrm{pT}$. The analysis of only those discrete events which exceed the natural noise background by a factor of 3 is recommended [Jones and Kemp, 1971]. Therefore, the events are divided for analysis into two groups of high (i.e., $B_{h}>6$ pT, labeled 'o') and low (i.e., $B_{h} \leq 6 \mathrm{pT}$, labeled ' $\times$ ') horizontal magnetic intensity (Table 1 , column 8 ).

The enhancement of the Earth-ionosphere cavity resonances is apparent from spectral comparison between discrete events with low and with high horizontal magnetic intensities. A 0:50-s interval beginning at the time of the sprite-associated lightning flash is chosen for analysis, resulting in a spectral resolution of $2 \mathrm{~Hz}$. Figure 3 shows the mean spectral horizontal magnetic intensity

$$
B_{h}(f)=<\sqrt{B_{x}^{2}(f)+B_{y}^{2}(f)}>
$$

for each group of events, where the error bars denote the standard deviation of the mean. The lower bars reflect the mean spectrum of the noise background, and the upper bars exhibit the enhancement of the first two Earth-ionosphere cavity resonances at 8 and $14 \mathrm{~Hz}$ (Table 1, columns 9-10). These results confirm the temporal coincidence of sprite-associated lightning flashes and the enhancement of Earth-ionosphere cavity resonances at a measurement site $\sim 8000 \mathrm{~km}$ from the source.

The arrival azimuth of each discrete event is calculated from the time-domain waveform using the maximum of the horizontal magnetic intensity within the first 0.25 scconds after the occurrence of the lightning flash. The expected arrival azimuth is calculated from the known source locations (Table 1, columns 3-4) and from the orientation of the Poynting vector along the great-circle path. Unknown locations are replaced by the mean value of all known locations because the lightning locations are closely distributed compared to the source-receiver distance. Figure 4 shows for each event

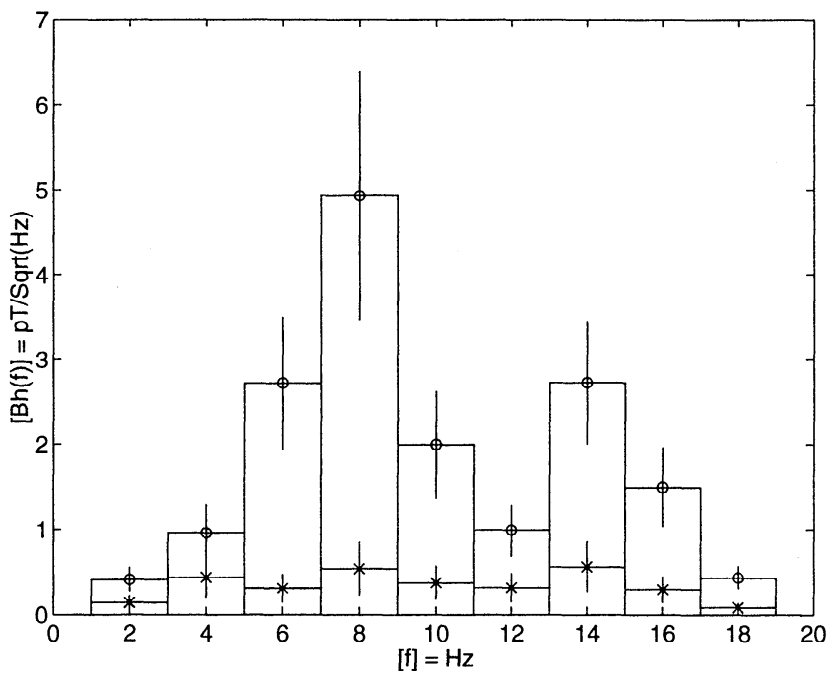

Figure 3. Mean spectra of discrete events at Silberborn. The mean spectrum $B_{h}(f)$ of the high intensity events is shown in the upper bars and labeled 'o', and the mean spectrum of the low intensity events is displayed in the lower bars and labeled ' $x$ '.

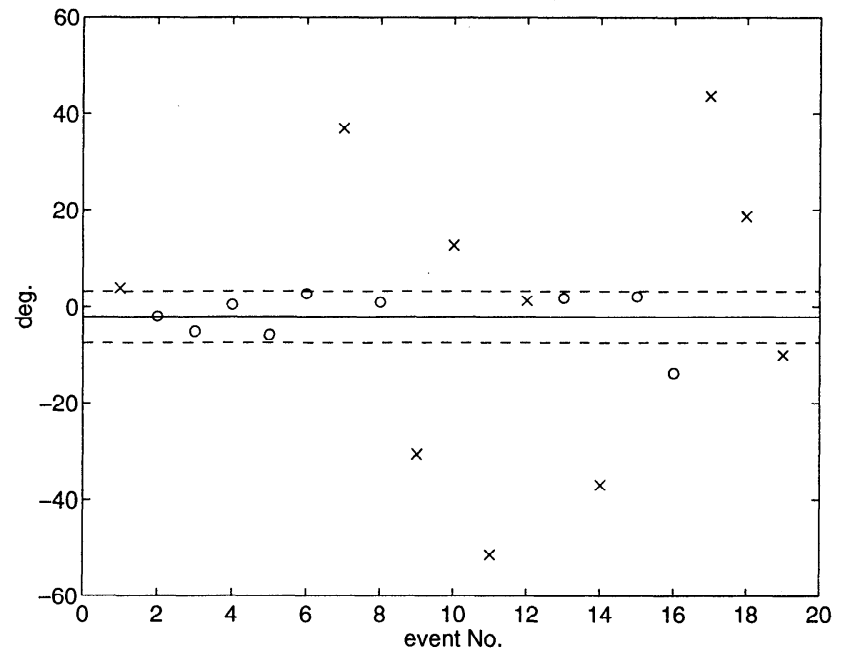

Figure 4. Deviation of the measured arrival azimuth from the expected value derived from the NLDN location for high and low intensity events, labeled 'o' and ' $x$ ' respectively.

the deviation of the measured arrival azimuth from the expected value. For discrete events with low horizontal magnetic intensity, background noise interference limits the accuracy of arrival azimuth determination and only a few reliable estimates were derived. Discrete events with high horizontal magnetic intensity exhibit a mean deviation of $-2.04^{\circ}$ from the expected arrival azimuth (solid line) with a standard deviation of $\pm 5.38^{\circ}$ (dashed lines). Compared to the angular great-circle distance of $71.50^{\circ}$, the estimated accuracy of the arrival azimuth determination is $\sim \pm 7.5 \%$.

\section{Discussion}

Simultaneous observations of horizontal magnetic field variations in the frequency range of the Earth-ionospherc cavity resonances and ELF slow tails at widely separated locations were investigated at the times of occurrence of sprite-associated lightning flashes. Although only 19 discrete events are included in the analysis, thus limiting its statistical significance, the results are consistent for the following reasons: The enhancements of mean horizontal magnetic intensity show temporal coincidence with sprite-associated lightning flashes and a linear relationship to horizontal magnetic intensities of independently observed slow tails. The discrete events exhibit decay times and spectra in agreement with Earth-ionosphere cavity resonances reported in the literature [Sentman, 1995]. A reasonable interpretation of the presented results is that spriteassociated lightning flashes can excite Earth-ionosphere cavity resonances. A possible mechanism is that lightning discharges with continuing current excite radio atmospheric slow tails [Wait, 1960] and Earth-ionosphere cavity resonances [Burke and Jones, 1996]. The arrival azimuth was estimated from the time of maximum horizontal magnetic intensity and is in agreement with the expected Poynting vector orientation along the greatcircle path. The deviation of the arrival azimuth from the expected value is on the order of $\pm 5^{\circ}$. The accuracy 
of arrival azimuth determination is naturally limited by the bandwidth of the instrument. In view of the relatively low sampling rate of the measurement system, the estimated deviation may represent an upper limit. Deviations of the arrival azimuth may also result from excited multiplets of the Earth-ionosphere cavity resonances [Sentman, 1987] or from modifications of the incident wave by accumulation of electrical charge along inhomogenities near the Earth's surface, termed galvanic distortion [Chave and Smith, 1994]. The accuracy of arrival azimuth determination shows that simultaneous observations of horizontal magnetic field variations at disparate locations around the world can be used to assess the global distribution of source locations of the Earth-ionosphere cavity resonances.

Acknowledgments. This research was sponsored by the Deutsche Forschungsgmeinschaft under Grant Fu 285/21 and the National Aeronautics and Space Administration under Grant NGT-30281 to Stanford University, and contract NAS10-12113 to ASTeR, Inc.. Data collection at Silberborn is sponsored by the Deutsche Forschungsgmeinschaft under Grant Schm 101/23-1 and at Palmer Station by the National Science Foundation under Grant OPP-9318596. The authors thank the MSFC/DAAC for access to selected periods of lightning data.

\section{References}

Boccippio, D.J., E.R. Williams, S.J. Heckman, W.A. Lyons, I.T. Baker, and R. Boldi, Sprites, ELF transients, and positive ground strokes, Science, 269, 1088, 1995.

Burke, C.P., and D.L. Jones, On the polarity and continuing currents in unusually large lightning flashes from ELF events, J. Atm. Terr. Phys., 58, 531, 1996.

Chave, A.D., and J.T. Smith, On electric and magnetic galvanic distortion tensor decomposition, J. Geophys. Res., 99, 4669, 1994.

Fukunishi, H., Y. Takahashi, M. Kubota, K. Sakanoi, U.S. Inan, and W.A. Lyons, Elves: Lightning-induced transient luminous events in the lower ionosphere, Geophys. Res. Lett., 23, 2157, 1996.
Füllekrug, M., Schumann resonances in magnetic field components, J. Atm. Terr. Phys., 57, 479, 1995.

Jones, D.L., and D.T. Kemp, Experimental and theoretical observation on the transient excitation of Schumann resonances, J. Atm. Terr. Phys., 32, 1095, 1970.

Jones, D.L., and D.T. Kemp, The nature and average magnitude of the sources of transient excitation of Schumann resonances, J. Atm. Terr. Phys., 33, 557, 1971.

Kemp, D.T., The global location of large lightning discharges from single station observations of ELF disturbances in the Earth-ionosphere cavity, J. Atm. Terr. Phys., 33, 919, 1971.

Lyons, W.A., Characteristics of luminous structures in the stratosphere above thunderstorms as imaged by low-light video, Geophys. Res. Lett., 21, 875, 1994.

Lyons, W.A., Sprite observations above the U. S. High Plains in relation to their parent thunderstrom systems, J. Geophys. Res., (in press), 1996.

Reising, S.C., U.S. Inan, T.F. Bell and W.A. Lyons, Evidence for continuing currents in sprite-producing lightning flashes, Geophys. Res. Lett., (in press), 1996.

Sentman, D.D., Magnetic elliptical polarization of Schumann resonances, Radio Science, 22, 595, 1987.

Sentman, D.D., and E.M. Wescott, Observations of upper atmospheric optical flashes recorded from an aircraft, Geophys. Res. Lett., 20, 2857, 1993.

Sentman, D.D., Schumann Resonances, pp. 267-310 in Handbook of Atmospheric Electrodynamics, Vol. I, Ed. H. Volland, CRC Press, Boca Raton, 1995.

Sentman, D.D., E.M. Wescott, D.L. Osborne, D.L. Hampton, and M.J. Heavner, Preliminary results from the Sprites94 aircraft campaign: 1. Red sprites, Geophys. Res. Lett., 22, 1205, 1995.

Wait, J.R., On the slow-tail portion of atmospheric waveforms, J. Geophys. Res., 65, 1939, 1960.

Winckler, J.R., Further observations of cloud-ionosphere electrical discharges above thunderstorms, J. Geophys. Res., 100, 14335, 1995

M. Füllekrug and S.C. Reising, STAR Laboratory,

Durand Building, Stanford University, Stanford, CA 94305

W.A. Lyons, ASTeR, Inc., 46050 Weld County Road 13, Ft. Collins, CO 80524

(Received May 28, 1995; accepted November 4, 1996.) 